\title{
Article
}

\section{Do psychobiosocial states mediate the relationship between perceived motivational climate and individual motivation in youngsters?}

Bortoli, Laura, Bertollo, Maurizio, Filho, Edson and Robazza, Claudio Available at http://clok.uclan.ac.uk/14157/

Bortoli, Laura, Bertollo, Maurizio, Filho, Edson ORCID: 0000-0002-8548-4651 and Robazza, Claudio (2013) Do psychobiosocial states mediate the relationship between perceived motivational climate and individual motivation in youngsters? Journal of Sports Sciences, 32 (6). pp. 572-582. ISSN 02640414

It is advisable to refer to the publisher's version if you intend to cite from the work.

For more information about UCLan's research in this area go to http://www.uclan.ac.uk/researchgroups/ and search for <name of research Group>.

For information about Research generally at UCLan please go to http://www.uclan.ac.uk/research/

All outputs in CLoK are protected by Intellectual Property Rights law, including Copyright law. Copyright, IPR and Moral Rights for the works on this site are retained by the individual authors and/or other copyright owners. Terms and conditions for use of this material are defined in the policies page. 
Do psychobiosocial states mediate the relationship between perceived motivational climate and individual motivation in youngsters?

Running head: Psychobiosocial states and motivations

Keywords: motivation, achievement goal theory, self-determination theory, IZOF model

Date of submission of the manuscript: March 6, 2013

Date of submission of the revised manuscript: June 3, 2013

Date of submission of the revised manuscript (second revision): July 18, 2013

Date of submission of the revised manuscript (third revision): August 5, 2013 


\begin{abstract}
Grounded in achievement goal theory and self-determination theory, this cross-sectional study examined the relationship between perceived motivational climate and individuals' motivation as well as the mediation effect of psychobiosocial states as conceptualized within the individual zones of optimal functioning (IZOF) model. Young students $(N=167$, age range $14-15$ years) taking part in physical education classes completed measures of teacher-initiated motivational climate, task and ego orientation, motivation, and psychobiosocial states. Simple and serial mediation analyses indicated that a perceived mastery climate and individuals' task orientation were related to intrinsic motivation and identified regulation through the mediation of pleasant/functional psychobiosocial states. In contrast, a perceived performance climate was related to external regulation and amotivation through the mediation of unpleasant/dysfunctional psychobiosocial states. Regression analysis results also showed that discrete psychobiosocial states accounted for a significant proportion of variance in motivational variables. Taken together, findings highlight the role of psychobiosocial states as mediators of the relationship between motivational climate and an individual's motivation, and suggest that educators should consider a wide range of individual's functional and dysfunctional reactions deriving from their instructional activity.
\end{abstract}

Keywords: motivation, achievement goal theory, self-determination theory, IZOF model 


\section{Introduction}

Motivating people to be physically active today is a crucial public health issue, and school physical education is acknowledged to play a main role in educating youngsters to adopt long-lasting healthy behaviours (see Ayers \& Sariscsany, 2011). Effective teaching strategies and a task-involving motivational climate can enhance students' enjoyment and motivation towards physical education. Enjoyment and motivation, indeed, have been shown to be related to youngsters' participation, learning, and improvement in physical activity (Biddle, Wang, Chatzisarantis, \& Spray, 2003; Biddle, Whitehead, O’Donovan, \& Nevill, 2005). Therefore, teachers may try to enhance enjoyment and other pleasant emotional states to increase pupils' interest in physical education and active behaviour (Wallhead \& Buckworth, 2004).

Emotions in sport and physical activity have been investigated in light of different theoretical approaches. One of the most prominent is the individual zones of optimal functioning (IZOF) model, which was developed by Hanin $(2000,2007)$ to describe, predict, explain, and enable control of individual optimal and dysfunctional performance states. The IZOF model has been mainly applied to the sport context. The emotional experiences and their display are conceived holistically and described as an array of performance-related psychobiosocial states. Hanin defined a psychobiosocial state as a situational, multimodal, and dynamic manifestation of total human functioning, in which emotion is construed in a multidimensional manner and as a fundamental component of an individual's experience. A psychobiosocial state is manifested through a range of interactive components that include psychological (emotional, cognitive, motivational), biological (bodily, motor-behavioural), and social (performance, communicative) aspects. These components can be individually experienced as pleasant or unpleasant (hedonic valence) and may exert either a functional or dysfunctional effect on performance process and outcome. This is 
consistent with the IZOF theory, in which emotional content is understood through the interaction of hedonic valence and performance functionality (see Hanin, 2007; Robazza, 2006). From this interaction, the following four global categories of psychobiosocial states emerge: pleasant-functional, unpleasant-functional, pleasantdysfunctional, and unpleasant-dysfunctional.

Within the IZOF model, emotion profiling involves the identification of idiosyncratic and task-specific psychobiosocial states as related to successful and less than successful performance experiences. Self-generated, relevant individual's adjectives are classified according to the four psychobiosocial state categories. In the current study, we opted for a structured questionnaire to optimize data collection in a relatively large sample size. In this questionnaire, emotional adjectives were classified a priori as either pleasant or unpleasant, whereas all other items (e.g., cognitive, motivational, motor-behavioural) were categorized as either functional or dysfunctional. For example, psychobiosocial state descriptors for the psychological aspect include: happy, joyful (pleasant emotions); worried, nervous (unpleasant emotions); alert, focused (functional cognitions); confused, distracted (dysfunctional cognitions); motivated, determined (functional motivations); and unmotivated, disengaged (dysfunctional motivations). While the hedonic valences of "joyful" (pleasant) or "worried" (unpleasant) have straightforward connotations, their functional effects are not implicitly obvious given that both pleasant and unpleasant emotions may be perceived as functional or dysfunctional to performance. On the other hand, the functional or dysfunctional effects of "alert" and "distracted" are likely to be intuitive. Nonetheless, hedonic valence may differ based on one's appraisal of personal abilities to master a given task.

Psychobiosocial states have been recently studied in youth sport (Bortoli, Bertollo, Comani, \& Robazza, 2011; Bortoli, Bertollo, \& Robazza, 2009; Bortoli, 
Messina, Zorba, \& Robazza, 2012) and physical education (Bortoli \& Robazza, 2007). In their research, the authors used the IZOF model and the achievement goal theory as frameworks to examine the relationship between psychobiosocial states and motivational variables (i.e., individual's goal orientation and perceived motivational climate). Achievement goal theory is a leading theoretical perspective in the study of motivation in sport, physical activity, physical education, and other achievement endeavours (Ames, 1992; Nicholls, 1984; Wang \& Biddle, 2007). There is evidence that this theory can explain and predict beliefs, responses, and behaviour in achievement settings, and that personal and situational factors can influence goal adoption (Treasure \& Roberts, 2001). For example, Bortoli and Robazza's (2007) findings suggested that task-oriented students (personal factor), who perceived a mastery-involving atmosphere during physical education lessons (situational factor), tended to experience high levels of pleasant/functional psychobiosocial states and low levels of unpleasant/dysfunctional states. Similarly, in a study among youth in sport, Bortoli et al. (2009) noted that taskoriented participants were likely to perceive more pleasant/functional states when mastery climate cues were high, or performance climate cues were low.

With regard to personal factors, Nicholls (1989) linked achievement goals to the development of a conception of ability, and contended that individuals could evoke at least two ways of construing their competence through the adoption of a task-involved and/or an ego-involved goal orientation. When task-involved, an individual's perception of ability is self-referenced because the focus is on achieving task mastery, gaining skill or knowledge, investing effort, progressing in learning, and performing one's best. When ego-involved, success is normatively referenced and the focus is on outperforming others, demonstrating superior competence, or performing equally well with less effort. Other scholars have used the terms mastery and performance goals to describe individual achievement goals (e.g., Elliot, 1999). In the 1990s and 2000s, Elliot 
and colleagues extended the dichotomous model of achievement goals by incorporating the notion of "the valence of the striving" (i.e., approaching success vs. avoiding failure). The $2 \times 2$ framework yielded mastery-approach, mastery-avoidance, performance-approach, and performance-avoidance goals (Elliot, 1999; Elliot \& Conroy, 2005; see Elliot, Murayama, \& Pekrun, 2011 for recent developments).

Concerning situational factors, the social situation created by significant others, physical education teachers included, can influence the likelihood of whether a person will be task- or ego-involved when participating in the activity (see Roberts, Treasure, \& Conroy, 2007). In sport or physical education settings, coaches or teachers create a task-involving atmosphere (i.e., mastery climate) when they emphasize effort exertion, learning, personal improvement, and teamwork, and view mistakes as intrinsically related to the learning process. However, educators create an ego-involving atmosphere (i.e., performance climate) when they place emphasis on highly competitive situations and rivalries in social exchanges, make public evaluation of skill level differences, use normatively-based feedback, reward only those who attain the best results, and use punishment for mistakes.

Research findings in physical activity and youth sport (see Ntoumanis \& Biddle, 1999) have indicated that adaptive cognitive, affective, and behavioural patterns are more probable when individuals are highly task-oriented and/or they are in a perceived mastery-involving climate. A number of studies have convincingly demonstrated that mastery climate and task orientation are related to well-being, sportspersonship, satisfaction, enhanced persistence in the face of failure, increased effort, engagement in challenging tasks, interest in self-improvement, and intrinsic motivation, notwithstanding the level of individuals' perceived or actual ability (e.g., Papaioannou, Ampatzoglou, Kalogiannis, \& Sagovits, 2008; for a review, see Keegan, Harwood, Spray, \& Lavallee, 2011). In contrast, a perceived performance-involving climate has 
been found to be related to less adaptive or maladaptive cognitive, affective, and behavioural responses, such as dissatisfaction, amotivation, task withdrawal, and reduced effort and persistence (Biddle, Wang, Kavussanu, \& Spray, 2003).

Self-determination theory (Deci \& Ryan, 1985) is another leading approach to the study of individual's motivation, with extensive applications within the sport and exercise context. Ntoumanis (2001) highlighted the theoretical links between achievement goal theory and self-determination theory, while also discussing empirical evidence on the relationship between goal orientation and different types of motivation. In particular, high task orientation can be expected to enhance self-determined motivation, whereas high ego orientation could weaken autonomy and foster an external locus of causality.

According to self-determination theory, various types of motivation underlying human behaviour differ in their levels of self-determination, construed as a sense of autonomy and freedom in what one has chosen to do. Placed on a continuum from high to low levels of self-determination, these motivations are intrinsic motivation, identified regulation, external regulation, and amotivation. Intrinsic motivation refers to taking part in an activity for its own sake, in order to experience pleasure and satisfaction derived from participation itself (Deci \& Ryan, 1985; Ryan \& Deci, 2000). Identified regulation is a form of extrinsic motivation. It occurs when a behaviour is valued and perceived as being chosen by oneself, although the activity is performed as a means to an end, not an end in itself. External regulation is another form of extrinsic motivation that is operative when behaviour is regulated by rewards, or is intended to avoid sanctions or other negative consequences. The individual feels forced to behave in a specific way. Finally, amotivation refers to a relative lack of motivation. When amotivated, individuals experience a lack of contingency between the behaviour and the outcomes of the action. Thus, they may feel that being involved in an activity is 
worthless (Vallerand, 2001). Amotivated behaviours are not self-determined because there is no sense of purpose and no expectation of reward from an activity. Research has shown that intrinsic motivation is a fundamental antecedent in the adoption of a physically active lifestyle (Standage \& Ryan, 2012). In contrast, amotivation is assumed to indicate a lack of interest in investing resources in physical activities.

The two theoretical perspectives aforementioned (i.e., achievement goal orientation and self-determination theory) share both theoretical and applied implications. Indeed, a mastery climate has been found to be related to intrinsic motivation and pleasant affective states in youth sport (e.g., Petherick \& Weigand, 2002) and physical education (e.g., Parish \& Treasure, 2003), whereas a performance climate has been linked to amotivation in youth sport (Ommundsen, Lemyre, Abrahamsen, \& Roberts, 2010).

Drawing from the conceptualization of psychobiosocial states within the IZOF model, achievement goal theory, and self-determination theory, we conducted a study with a sample of 14-15 year-old students involved in physical education at school. The purpose of this investigation was threefold. First, we examined the relationship between mastery climate and intrinsic motivation/identified regulation, as well as the mediation effect of pleasant/functional psychobiosocial states. We expected to find perceived mastery climate positively linked to both intrinsic motivation and identified regulation, because of the conceptual closeness of the two forms of motivation on the selfdetermination continuum. Pleasant/functional states associated with physical education activities were also expected to positively relate to mastery climate and intrinsic motivation/identified regulation, and to exert a mediating effect.

The second purpose was to investigate the relationship between performance climate and external regulation/amotivation, and the mediation effect of unpleasant/dysfunctional psychobiosocial states. We hypothesized that perceived 
performance climate would positively relate to both external regulation and amotivation, due to the conceptual proximity of the two forms of motivation on the selfdetermination continuum. Unpleasant/dysfunctional states were expected to positively relate to performance climate and external regulation/amotivation, and to exert a mediating effect.

A final objective was to explore what kind of psychobiosocial states were associated with motivational states. Specifically, we wanted to examine which discrete component of psychological (emotional, cognitive, motivational), biological (bodily, motor-behavioural), and social (performance, communicative) states was predictive of individual motivation as classified along the self-determination continuum (i.e., intrinsic motivation, identified regulation, external regulation, and amotivation). Compared to global measures of affect, the assessment of pleasant/functional and unpleasant/dysfunctional states enables to ascertain the possible range of individual's reactions to a physical education motivational climate.

\section{Method}

\subsection{Participants}

Participants were 167 students, 85 girls and 82 boys, aged 14-15 years $(M=$ 14.51 yrs., $S D=.52$ ) recruited from three high schools located in three towns in northeastern Italy. Students were involved in physical education as a mandatory course twice a week during their first year of high school. Following the explanation of the general purposes of the research, the headmaster and teachers gave permission to conduct the study. Participants and their parents gave their assent, and the latter also signed an informed consent. The ethics committee of the local university approved the study.

\subsection{Measures}

\subsubsection{The Teacher-Initiated Motivational Climate in Physical Education}

\section{Questionnaire}


The Teacher-Initiated Motivational Climate in Physical Education Questionnaire (Papaioannou, 1998) has 12 items organized into two 6-item scales. The teacherinitiated mastery orientation scale assesses the teacher's emphasis on skill mastery and effort (e.g., "The physical education teacher is most satisfied when every student learns something new"), whereas the teacher-initiated performance orientation scale evaluates the teacher's emphasis on social comparison and competition (e.g., "Only the students with the best records are rewarded"). Pupils are asked to think about their physical education class and indicate their responses on a 5-point scale ranging from 1 "strongly disagree" to 5 "strongly agree". We used an Italian version of the Teacher-Initiated Motivational Climate in Physical Education Questionnaire in this study, which in a previous research was administered to boys and girls aged from 11 to 14 years (Bortoli, Colella, Morano, Berchicci, Bertollo, \& Robazza, 2008). Confirmatory factor analysis supported the two-dimensional structure of the questionnaire. Cronbach $\alpha$ values for the mastery and performance scale scores were .79 and .70 , respectively.

\subsubsection{The modified Task and Ego Orientation in Sport Questionnaire}

Duda and Nicholls (1992) developed the Task and Ego Orientation in Sport Questionnaire to assess task and ego involvement in the athletic domain. Walling and Duda (1995) subsequently modified the questionnaire for use within the physical education context. The modified questionnaire includes 16 items. The stem of items is "I feel really successful in physical education when..." Eight items measure individuals' disposition for ego orientation (e.g., “...I'm the best”) and eight items gauge individuals' disposition for task orientation (e.g., “...I do my very best”). Participants are asked to respond to each item on a 5-point scale anchored by 1 "strongly disagree" and 5 "strongly agree". We used an Italian version of the modified Task and Ego Orientation in Sport Questionnaire in our study. In an earlier study, Bortoli and Robazza (2005) translated into Italian the modified version of the 
questionnaire and administered it to boys and girls ranging in age from 14 to 19 years. Confirmatory factor analysis yielded acceptable fit indexes for the two-factor solution. Internal consistency was good, with Cronbach $\alpha$ values of .92 for the ego factor scores and .83 for the task factor scores.

\subsubsection{The Situational Motivation Scale}

Guay, Vallerand, and Blanchard (2000) proposed the Situational Motivation Scale to assess the constructs of intrinsic motivation, identified regulation, external regulation, and amotivation deriving from the self-determination theory (Deci \& Ryan, 1985). Each construct is represented by a 4-item subscale. Example of items are: "I think that this activity is pleasant" (intrinsic motivation), "I believe that this activity is important for me" (identified regulation), "it is something that I have to do" (external regulation), and "I do this activity but I am not sure if it is worth it" (amotivation). The stem of items is "...please circle the number that best describes the reason why you are currently engaged in this activity". Each item is scored on a 7-point scale ranging from 1 "corresponds not all" to 7 "corresponds exactly". The authors found evidence that the 16-item scale is composed of four identifiable factors reflecting the theorized constructs of self-determination theory. Cronbach's $\alpha$ values of the subscale scores ranged from .77 to .95 .

The Situational Motivation Scale was translated into Italian using the backward translation technique. Specifically, two Italian researchers fluent in English independently translated the scale from English into Italian. The two researchers discussed their translations until they reached agreement on all items. The translated scale was then retranslated into English by a professional translator who was a native English speaker. Subsequently, the two researchers examined carefully the translated and retranslated texts to check the accuracy of each and to reach consensus on the Italian version of the scale. Finally, three additional researchers were asked to read the 
items to make sure they reflected the original meaning. A confirmatory factor analysis was performed on the data of this study with SPSS AMOS 21 (Arbuckle, 2012). The model parameters were estimated using the maximum likelihood function. Results on the whole sample suggested adequate fit to the data, $\chi^{2}(98)=384.263, \chi^{2} / \mathrm{df}=3.921$, $\mathrm{GFI}=.918, \mathrm{CFI}=.936 ; \mathrm{RMSEA}=.059(90 \% \mathrm{CI}=.035-.070)$, with item-factor loadings ranging from .47 to .96 .

\subsubsection{Psychobiosocial states}

Bortoli and Robazza (2007) proposed a 14-item list of pleasant/functional descriptors (seven items) and unpleasant/dysfunctional descriptors (seven items) to assess psychobiosocial states in the physical education domain. Descriptors were derived from a number of adjectives pertaining to each of the seven psychobiosocial components conceptualized within the IZOF model (Hanin, 2000) and based on existing lists of descriptors used to assess emotional experiences in youth sport and physical education (e.g., Robazza \& Bortoli, 2005; Robazza, Bortoli, Carraro, \& Bertollo, 2006). An item (discrete psychobiosocial state) was composed of two or three descriptors, rather than just one descriptor, in order to convey a clear and straightforward representation of an emotional experience related to the physical education context. The items were randomly arranged in the questionnaire. Pleasant/functional or unpleasant/dysfunctional items for each psychobiosocial component were: "happy, joyful, cheerful", and "depressed, sad" (emotion; items 1 and 7); "convinced, resolute, purposeful", and "inactive, sluggish, passive" (cognition; items 8 and 2); "involved, determined, committed", and "unmotivated, disengaged" (motivation; items 13 and 3); "physically fresh, reactive", and "tense, stiff muscles" (bodily reaction; items 14 and 4); "active, dynamic", and "awkward, clumsy" (movement; items 9 and 11); "capable, proficient, effective", and "doubtful, unsure, uncertain" (performance; items 12 and 5); "socializing, collaborative", and "lonely, isolated" (communication; items 6 and 10). 
Participants were asked to rate each item on a five-point scale, ranging from 0 "not at all" to 4 "very, very much", thinking of how they usually feel within their physical education context. Bortoli and Robazza (2007) showed a two-factor solution (i.e., pleasant/functional and unpleasant/dysfunctional dimensions) to be acceptable.

Cronbach $\alpha$ values were .84 for the pleasant scale scores and .72 for the unpleasant scale scores.

\subsection{Procedure}

Data were collected in small groups of four or five participants involved in physical education lessons, and took place in a quiet location near to the physical education facilities without the presence of the teacher. Participants were informed about their voluntary status, and ensured confidentiality. They were asked to fill out the questionnaires thinking about their current experience in physical education. We also presented social desirability instructions while emphasizing the need for honesty, and told students that there were no right or wrong answers. After having asked participants to complete the questionnaires, we remained available to clarify possible doubts or misunderstandings.

\subsection{Data Analysis}

Data were checked to examine the assumptions of normality, linearity, multicollinearity, and homogeneity of variance-covariance matrices through frequency and scatter plots, and Box's $M$-test. Gender differences on the variable scores were then scrutinized through multivariate analysis of variance (MANOVA) and follow-up univariate tests. Descriptive statistics, internal consistency, and correlation coefficients were computed for all measures.

The main objective of the study was to examine whether pleasant/functional or unpleasant/dysfunctional psychobiosocial states (aggregated categories) mediated the relationship between motivational climate and the individual's motivation. The possible 
mediation of individuals' dispositional goal orientation (i.e., task and ego) was also considered. For this purpose, we conducted both simple and serial mediation analyses using the Hayes' (2012) PROCESS computational tool for SPSS, which enables estimation of path coefficients, standards errors, different indexes of effect size, as well as bootstrap confidence intervals for the indirect effects based on 5,000 resamples (Preacher \& Hayes, 2008; Preacher \& Kelley, 2011). Following Preacher and Kelley's (2011) recommendations, we used $\kappa^{2}$ and $a b_{c s}$ as indexes of effect size of simple and multiple effects, respectively. Both indexes are standardized and insensitive to sample size.

Finally, four regression analyses were conducted to determine which of the discrete psychobiosocial states predicted intrinsic motivation, identified regulation, external regulation, and amotivation. Gender was dummy coded $(0=$ boys, $1=$ girls $)$ and included as a covariate in step 1. In step 2, the seven pleasant/functional psychobiosocial states were entered as independent variables, using the stepwise method, to predict intrinsic motivation or identified regulation. Likewise, the seven unpleasant/dysfunctional states were entered in step 2 to predict external regulation or amotivation.

\section{Results}

\subsection{Descriptive Statistics and Correlations}

Two boys and two girls were identified as multivariate outliers and, therefore, excluded from further analysis. The final sample comprised 83 girls and 80 boys. Their data did not show substantial departures from the assumptions required for subsequent analyses. MANOVA results yielded significant differences by gender, Wilks’ $\lambda=.62, F$ $(10,152)=9.35, p<.001, \eta_{p}^{2}=.38$, power $=1.00$. Follow-up univariate analysis $(p<$ .01) showed that boys reported higher scores on perceived performance climate, egoorientation, amotivation, and pleasant/functional psychobiosocial states than did girls, 
and lower scores on perceived mastery climate. Table 1 contains scale reliabilities, descriptive statistics, and correlation coefficients. Partial correlations were calculated to control for any potential gender effects. As can be observed, scores of perceived mastery climate, task orientation, pleasant/functional states, and intrinsic motivation/identified regulation were larger than scores of perceived performance climate, ego orientation, unpleasant/dysfunctional states, and external regulation/amotivation respectively.

For the purpose of our study, it is worth noting that mastery climate correlated positively with pleasant/functional states, intrinsic motivation, and identified regulation, while performance climate related positively to unpleasant/dysfunctional states, external regulation, and amotivation. Furthermore, positive correlations were found between intrinsic motivation and identified regulation, and between external regulation and amotivation, whereas all other interrelations among variables were negative. This pattern of relationships provides support to the validity of the self-determination continuum, whereby adjacent variables are expected to interrelate positively, and variables at the opposite ends of the continuum are expected to correlate negatively (Ryan \& Connell, 1989).

\subsection{Mediation Analysis}

\subsubsection{Mastery climate and intrinsic motivation/identified regulation}

The first mediation analysis was conducted to examine whether the effect of perceived mastery climate on intrinsic motivation was mediated by pleasant/functional psychobiosocial states (first objective of the study). Simple mediation analysis showed that the effect of mastery climate on intrinsic motivation was reduced when the pleasant/functional states variable was included in the model. The indirect effect via pleasant/functional states was $\kappa^{2}=.219$, with a point and bias corrected $95 \%$ CI of .133 to .316 . Preacher and Kelley (2011) suggested that $\kappa^{2}$ be interpreted with CIs in terms of 
Cohen's (1988) effect size indications for squared correlation coefficients, with values of $.01, .09$, and .25 , representing small, medium, and large effect sizes, respectively. In our study, the mediation effect was medium-to-large because the CI was $>.09$ and included .25. Mastery climate and pleasant/functional states explained together $46.3 \%$ of the variability in intrinsic motivation, $F(2,160)=68.85, p<.001$, each of them making a significant contribution: standardized direct effect of mastery climate, $\beta=.27$, $t(162)=4.34, p<.001 ;$ standardized direct effect of pleasant/functional states, $\beta=.53$, $t(162)=8.34, p<.001$.

The possible mediation of individuals' task orientation was then assessed, and task orientation introduced as a mediator in the model using serial mediation analysis (see Figure 1, upper panel). The completely standardized indirect effect of mastery climate on intrinsic motivation, passing through both task orientation and pleasant/functional states, was significant, with $a b_{c s}=.123$, with a resulting bootstrap CI of .066 to .217. Although task orientation did not contribute significantly to the explained variability in intrinsic motivation, $\beta=.05, t<1$, the linkage with pleasant/functional states was statistically significant.

In like manner, simple and serial mediation analyses were performed to ascertain whether the effect of perceived mastery climate on identified regulation was mediated by task orientation and pleasant/functional psychobiosocial states. Findings were consistent with those regarding intrinsic motivation (Figure 1, lower panel). The indirect effect of mastery climate on identified regulation via psychobiosocial states was $\kappa^{2}=$ .147 , with a $95 \%$ CI of .08 to .23 . Mastery climate and psychobiosocial states explained together $20.1 \%$ of the variability in identified regulation, $F(2,160)=20.17, p<.001$. The completely standardized indirect effect of mastery climate on intrinsic motivation via task orientation and pleasant/functional states was statistically significant, with $a b_{c s}$ $=.095$, and a CI of .045 to .183 . 
Taken together, these findings suggest that the perception of enhanced mastery climate, in conjunction with higher levels of individuals' task orientation, translates into enhanced pleasant/functional psychobiosocial states, which in turn lead to greater intrinsic motivation.

\subsubsection{Performance climate and external regulation/amotivation}

An additional analysis was conducted to explore the relation of perceived performance climate and unpleasant/dysfunctional psychobiosocial states to external regulation/amotivation (second objective of the study). Ego orientation was not introduced as a mediator in the model because of the non-significant correlations between ego orientation and external regulation or amotivation.

Simple mediation analysis showed a reduced effect of performance climate on external regulation when the unpleasant/dysfunctional states variable was added to the model (Figure 2, upper panel). The indirect effect was $\kappa^{2}=.126$, with a $95 \%$ CI of .054 to .213. Thus, the mediation effect was small-to-medium because the CI was $>.01$ and included .09. Performance climate and psychobiosocial states explained together $16.6 \%$ of the variability in external regulation, $F(2,160)=15.90, p<.001$. Analysis of amotivation yielded similar results. A reduced effect of performance climate on amotivation was shown when the psychobiosocial states variable was added (Figure 2, lower panel). The indirect effect was $\kappa^{2}=.113$, with a $95 \% \mathrm{CI}$ of .057 to .189 . Performance climate and psychobiosocial states predicted together $26.4 \%$ of the variability in amotivation, $F(2,160)=28.73, p<.001$, with a significant contribution: performance climate standardized direct effect, $\beta=.33, t(162)=4.51, p<.001$; unpleasant/dysfunctional states standardized direct effect, $\beta=.29, t(162)=3.88, p<$ .001 .

\subsection{Regression Analysis}


The aim of regression analysis was to establish which psychobiosocial states were better predictors of motivational states (third objective of the study). Intrinsic motivation and identified regulation were entered separately in the analysis as dependent variables, while pleasant/functional items (discrete psychobiosocial states) were included as predictors. The same analysis was performed for external regulation and amotivation as dependent variables, and unpleasant/dysfunctional items as predictors. Results are presented in Table 2. Movement, communication, and bodily reaction functional descriptors were significant predictors of intrinsic motivation and identified regulation. Pleasant emotion adjectives also accounted for a significant amount of variance in intrinsic motivation. In addition, movement, communication, and performance dysfunctional adjectives were found to be predictors of both external regulation and amotivation. Dysfunctional cognition descriptors also accounted for a portion of variance in external regulation.

\section{Discussion}

In this research we examined the relationships of perceived motivational climate with psychobiosocial states and motivations in physical education. We found support for the hypothesized links among mastery climate, pleasant/functional psychobiosocial states, and intrinsic motivation/identified regulation, as well as among performance climate, unpleasant/dysfunctional psychobiosocial states, and external regulation/amotivation. In summary, results indicate that perceived mastery climate and individuals' task orientation lead to greater intrinsic motivation and identified regulation through the mediation of pleasant/functional states. Moreover, a perceived performance climate leads to external regulation and amotivation through the mediation of unpleasant/dysfunctional states. Findings are consistent with previous studies showing that mastery-involving motivational climate is associated with adaptive cognitive, affective, and behavioural responses, such as task involvement (e.g., Biddle, Cury, 
Goudas, Sarrazin, Famose, \& Durand, 1995), intrinsic motivation, identified regulation (Goudas, 1998), and enjoyment (Ntoumanis \& Biddle, 1999). Research has also shown that performance-involving motivational climate is related to maladaptive outcomes such as ego involvement (Newton \& Duda, 1993), external regulation, amotivation (Ommundsen et al., 2010), and decreased enjoyment (Ntoumanis \& Biddle, 1999).

Taken as a whole, these studies underscore the central role of social agents (such as the teacher in the physical education context) in establishing an appropriate motivational climate for learning (see Vanden Auweele, Bakker, Biddle, Durand, \& Seiler, 1999). In particular, if youngsters perceive educators' support as predominantly mastery-oriented (i.e., emphasizing learning processes, improvement, and effort), they are likely to enjoy themselves, derive satisfaction from personal progress, be involved in the activity for its own sake and, ultimately, be intrinsically motivated toward participation in physical education (Ames, 1992; Duda, 2001). Conversely, performance-oriented climate (i.e., emphasizing competition, winning, and social comparison) tends to create unpleasant feelings, enhance amotivation, and determine withdrawal from the task.

The results of our study showed that psychobiosocial states mediated the relationship between perceived motivational climate and motivation. Achievement goal researchers have adopted measures to assess constructs related to pleasant emotional states, such as enjoyment, satisfaction, interest, positive affect, and flow, and unpleasant emotional states, such as anxiety, distress, negative thoughts, negative affect, and boredom (e.g., Biddle et al., 2003; Mouratidis, Vansteenkiste, Lens, \& Vanden Auweele, 2009). Bortoli and colleagues were the first to examine the feasibility and the benefits of investigating pleasant/functional and unpleasant/dysfunctional psychobiosocial states as related to motivational climate and individuals' achievement goals in youth sport (Bortoli et al., 2009, 2011, 2012) and physical education (Bortoli \& 
Robazza, 2007). In these studies, however, motivational climate and individuals' goals were used as predictors of psychobiosocial states, which were entered as outcome variables in the analyses. Bortoli et al. (2009), for example, showed that perceived mastery climate and task orientation related positively to most components of pleasant/functional states. Furthermore, interaction terms indicated that task orientation was associated with a higher level of pleasant/functional states when mastery climate cues were high. These results concur with those of the present study inasmuch as task orientation partially mediated the influence of mastery climate on pleasant/functional states. Our findings also showed that these three variables together accounted for a significant proportion of variance in intrinsic motivation and identified regulation. Results are also coherent with the "matching hypothesis", which suggests that individuals engaged in environments consistent with their own achievement goals are likely to experience pleasant states and be intrinsically motivated, while also displaying more self-determined forms of behavioural regulation (Jagacinski, Madden, \& Reider, 2001).

In agreement with the view that task-oriented people are likely to display adaptive motivational responses, individuals' task orientation correlated positively with mastery climate, pleasant/functional states, intrinsic motivation, and identified regulation, whereas they related negatively to performance climate, unpleasant/dysfunctional states, external regulation, and amotivation (see Table 1). However, individuals' ego orientation did not relate to any other variable assessed in the study and, thus, was not entered in mediation analysis. The lack of statistically significant relationships is likely due to different levels of perceived competence of egooriented participants in our sample. This interpretation concurs with achievement goal theory assumptions. According to achievement goal theory (Nicholls, 1984), taskoriented persons are expected to exhibit adaptive behaviours regardless of their levels of 
perceived competence. Adaptive behaviours are also expected in ego-oriented individuals, but only when the level of perceived competence is high. When perceived competence is low, ego-oriented persons are likely to adopt maladaptive motivational responses (e.g., amotivation and avoidance behaviour) because they tend to be concerned about their ability in comparison with others. In our sample, therefore, the lack of significant relationships among ego-orientation and the other variables may be related to a range of adaptive or maladaptive motivational responses resulting from different levels of perceived competence.

Regarding discrete psychobiosocial states, "active, dynamic" (functional movement), "socializing, collaborative" (functional communication), and "fresh, reactive" (functional bodily reaction) were significant predictors of both intrinsic motivation and identified regulation (see Table 2). "Happy, joyful, cheerful" (pleasant emotion) also accounted for a significant amount of variance in intrinsic motivation. Furthermore, "awkward, clumsy" (dysfunctional movement), "lonely, isolated" (dysfunctional communication), "depressed, sad" (unpleasant emotion), and "doubtful, unsure, uncertain" (dysfunctional performance) were predictors of both external regulation and amotivation. "Inactive, sluggish, passive" (dysfunctional cognition) also accounted for a portion of the variance in external regulation. Given that psychobiosocial states mediated the link between motivational climate and individuals' motivation, findings suggest that a mastery climate promotes adaptive psychobiosocial patterns typified by functional movement, communication, bodily reactions, pleasant emotions and, as a consequence, self-determined behaviour. Results also suggest that a performance climate fuels maladaptive patterns and an unpleasant condition typified by dysfunctional movement, poor communication, and the like. Of course, both functional and dysfunctional reactions are relevant in physical activity contexts. Practitioners need to carefully consider the individual's functional and dysfunctional reactions deriving 
from their interventions, while planning their activities to create an effective and enjoyable environment for learning and improvement.

\subsection{Limitations and Future Directions}

The current study provides an initial step in addressing the causal links of psychobiosocial states to motivational variables. Essentially, findings suggest that a mastery-involving atmosphere tends to elicit a variety of adaptive states enhancing motivation towards physical activity. In contrast, a performance-involving climate is likely to induce a number of maladaptive states potentially hindering motivation. Results also indicate that, rather than limiting attention to global affective responses, it is important to consider the entire range of performance-related psychobiosocial states to gain a broader understanding of one's idiosyncratic emotional experiences and reactions.

Notwithstanding, some limitations warrant attention for future research. First, due to the cross-sectional design of this study, it is not possible to derive definitive conclusions regarding the causal relations among the variables. Stronger evidence may be gained through longitudinal or intervention designs in which motivational climate is the focal variable manipulated (for a recent meta-analysis in physical education, see Braithwaite, Spray, \& Warburton, 2011). Second, the effect of perceived competence was not investigated. This relevant construct in achievement goal theory is expected to mediate emotional responses. As noted, the lack in our sample of significant links among ego-orientation and the other variables was probably due to a range of different levels of perceived competence. Thus, research on psychobiosocial states should incorporate this variable as well other relevant variables that may mediate the impact of social factors on motivation, such as the individual's satisfaction of psychological needs for autonomy, competence, and relatedness (Vallerand, 2001). Third, we used a dichotomous model of achievement goals. Recent developments of the achievement 
goal theory suggest the inclusion of other factors, such as competence (i.e., task/mastery vs. ego/performance) and valence of the striving (i.e., approaching success vs. avoiding failure; see Elliot et al., 2011). Finally, the assessment of psychobiosocial states involved seven pleasant/functional and seven unpleasant/dysfunctional components included in a validated scale developed within the IZOF theoretical perspective (Hanin, 2000). Hanin (2010) has recently revised the conceptualization of psychobiosocial states through the introduction of a new modality named volitional. This new modality should be considered in the future. We invite researchers to take a broad perspective, encompassing the interrelated psychobiosocial modalities, when studying individuals' states associated with achievement goals and motivation. 


\section{References}

Ames, C. (1992). Achievement goals, motivational climate, and motivational processes. In G. C. Roberts (Ed.), Motivation in sport and exercise (pp. 161-176). Champaign, IL: Human Kinetics.

Arbuckle, J. L. (2012). IBM ${ }^{\circledR}$ SPSS $^{\circledR}$ Amos $^{\mathrm{TM}} 21$ user's guide. Chicago, IL: SPSS.

Ayers, S. F., \& Sariscsany, M. J. (Eds.). (2011). Physical education for lifelong fitness (3rd ed.). Champaign, IL: Human Kinetics.

Biddle, S., Cury, F., Goudas, M., Sarrazin, P., Famose, J., \& Durand, M. (1995). Development of scales to measure perceived physical education class climate: A cross national project. British Journal of Educational Psychology, 65, 341-358.

Biddle, S. J. H., Wang, J. C. K., Chatzisarantis, N. L. D., \& Spray, C. M. (2003). Motivation for physical activity in young people: Entity and incremental beliefs about athletic ability. Journal of Sports Sciences, 21, 973-989. doi: $10.1080 / 02640410310001641377$

Biddle, S. J. H., Wang, C. K. J., Kavussanu, M., \& Spray, C. M. (2003). Correlates of achievement goal orientations in physical activity: A systematic review of research. European Journal of Sport Science, 3, 1-20.

Biddle, S. J. H., Whitehead, S. H., O’Donovan, T. M., \& Nevill, M. E. (2005). Correlates of participation in physical activity for adolescent girls: A systematic review of recent literature. Journal of Physical Activity and Health, 2, 423-434.

Bortoli, L., Bertollo, M., Comani, S., \& Robazza, C. (2011). Competence, achievement goals, motivational climate, and pleasant psychobiosocial states in youth sport. Journal of Sports Sciences, 29, 171-180. doi: 10.1080/02640414.2010.530675

Bortoli, L., Bertollo, M., \& Robazza, C. (2009). Dispositional goal orientations, motivational climate, and psychobiosocial states in youth sport. Personality and Individual Differences, 47, 18-24. doi: 10.1016/j.paid.2009.01.042. 
Bortoli, L., Colella, D., Morano, M., Berchicci, M., Bertollo, M, \& Robazza, C. (2008). Teacher-Initiated Motivational Climate in Physical Education questionnaire in an Italian sample. Perceptual and Motor Skills, 106, 207-214. doi: 10.2466/PMS.106.1.207-214

Bortoli, L., Messina, G., Zorba, M., \& Robazza, C. (2012). Contextual and individual influences on antisocial behaviour and psychobiosocial states of youth soccer players. Psychology of Sport and Exercise, 13, 397-406. doi:

10.1016/j.psychsport.2012.01.001

Bortoli, L., \& Robazza, C. (2005). Italian version of the Task and Ego Orientation in Physical Education Questionnaire. Perceptual and Motor Skills, 101, 901-910. doi: 10.2466/pms.101.3.901-910

Bortoli, L., \& Robazza, C. (2007). Dispositional goal orientations, motivational climate, and psychobiosocial states in physical education. In L. A. Chiang (Ed.), Motivation of exercise and physical activity (pp. 119-133). New York, NY: Nova Science.

Braithwaite, R., Spray, C. M., \& Warburton, V. E. (2011). Motivational climate interventions in physical education: A meta-analysis. Psychology of Sport and Exercise, 12, 628-638. doi: 10.1016/j.psychsport.2011.06.005

Cohen, J. (1988). Statistical power analysis for the behavioral sciences (2nd ed.). New York, NY: Academic Press.

Deci, E. L., \& Ryan, R. M. (1985). Intrinsic motivation and self-determination in human behavior. New York: Plenum Publishing Co.

Duda, J. L. (2001). Achievement goal research in sport: Pushing the boundaries and clarifying some misunderstandings. In G. C. Roberts (Ed.), Advances in motivation in sport and exercise (pp. 129-182). Champaign, IL: Human Kinetics. 
Duda, J. L., \& Nicholls, J. G. (1992). Dimensions of achievement motivation in schoolwork and sport. Journal of Educational Psychology, 84, 290-299. doi: 10.1037/0022-0663.84.3.290

Elliot, A. J. (1999). Approach and avoidance motivation and achievement goals. Educational Psychologist, 34, 169-189. doi: 10.1207/s15326985ep3403_3

Elliot, A. J., \& Conroy, D. E. (2005). Beyond the dichotomous model of achievement goals in sport and exercise psychology. Sport and Exercise Psychology Review, $1,17-25$.

Elliot, A. J., Murayama, K., \& Pekrun, R. (2011). A $3 \times 2$ achievement goal model. Journal of Educational Psychology, 103, 632-648. doi: 10.1037/a0023952

Goudas, M. (1998). Motivational climate and intrinsic motivation of young basketball players. Perceptual and Motor Skills, 86, 323-327.

Guay, F., Vallerand, R. J., \& Blanchard, C. (2000). On the assessment of situational intrinsic and extrinsic motivation: The Situational Motivation Scale (SIMS). Motivation and Emotion, 24, 175-213. doi: 10.1023/A:1005614228250

Hanin, Y. L. (Ed.). (2000). Emotions in sport. Champaign, IL: Human Kinetics.

Hanin, Y. L. (2007). Emotions in sport: Current issues and perspectives. In G. Tenenbaum, \& R. Eklund (Eds.), Handbook of sport psychology (3rd ed.). (pp. 31-58) Hoboken, NJ: Wiley.

Hanin, Y. L. (2010). Coping with anxiety in sport. In A. Nicholls (Ed.), Coping in sport: Theory, methods, and related constructs (pp. 159-175). New York: Nova Science.

Hayes, A. F. (2012). PROCESS: A versatile computational tool for observed variable mediation, moderation, and conditional process modeling [White paper]. Retrieved December 27, 2012, from http://www.afhayes.com/public/process2012.pdf 
Jagacinski, C. M., Madden, J. L., \& Reider, M. H. (2001). The impact of situational and dispositional achievement goals on performance. Human Performance, 14, 321337. doi: 10.1207/S15327043HUP1404_3

Keegan, R., Harwood, C., Spray, C., \& Lavallee, D. (2011). From 'motivational climate' to 'motivational atmosphere': A review of research examining the social and environmental influences on athlete motivation in sport. In B. D. Geranto (Ed.), Sport psychology (pp. 1-69). New York, NY: Nova Science.

Mouratidis, A., Vansteenkiste, M., Lens, W., \& Vanden Auweele, Y. (2009). Beyond positive and negative affect: Achievement goals and discrete emotions in the elementary physical education classroom. Psychology of Sport and Exercise, 10, 336-343. doi: 10.1016/j.psychsport.2008.11.004

Newton, M., \& Duda, J. L. (1993). Elite adolescent athletes' achievement goals and beliefs concerning success in tennis. Journal of Sport and Exercise Psychology, $15,437-448$.

Nicholls, J. G. (1984). Achievement motivation: Conceptions of ability, subjective experience, task choice, and performance. Psychological Review, 91, 328-346.

Nicholls, J. G. (1989). The competitive ethos and democratic education. Cambridge, MA: Harvard University Press.

Ntoumanis, N. (2001). Empirical links between achievement goal theory and selfdetermination theory in sport. Journal of Sports Sciences, 19, 397-409. doi: $10.1080 / 026404101300149357$

Ntoumanis, N., \& Biddle, S. J. H. (1999). A review of motivational climate in physical activity. Journal of Sports Sciences, 17, 643-665.

Ommundsen, Y., Lemyre, P.-N., Abrahamsen, F., \& Roberts, G. C. (2010). Motivational climate, need satisfaction, regulation of motivation and subjective 
vitality: A study of young soccer players. International Journal of Sport Psychology, 41, 216-242.

Papaioannou, A. (1998). Students' perceptions of the physical education class environment for boys and girls and the perceived motivational climate. Research Quarterly for Exercise and Sport, 69, 267-275.

Papaioannou, A. G., Ampatzoglou, G., Kalogiannis, P., \& Sagovits, A. (2008). Social agents, achievement goals, satisfaction and academic achievement in youth sport. Psychology of Sport and Exercise, 9, 122-141. doi: 10.1016/j.psychsport.2007.02.003

Parish, L. E., \& Treasure, D. C. (2003). Physical activity and situational motivation in physical education: Influence of the motivational climate and perceived ability. Research Quarterly for Exercise and Sport, 74, 173-182.

Petherick, C. M., \& Weigand, D. A. (2002). The relationship of dispositional goal orientations and perceived motivational climates on indices of motivation in male and female swimmers. International Journal of Sport Psychology, 33, 218237.

Preacher, K. J., \& Hayes, A. F. (2008). Asymptotic and resampling strategies for assessing and comparing indirect effects in multiple mediator models. Behavior Research Methods, 40, 879-891. doi: 10.3758/BRM.40.3.879

Preacher, K. J., \& Kelley, K. (2011). Effect size measures for mediation models: Quantitative strategies for communicating indirect effects. Psychological Methods, 16, 93-115. doi: 10.1037/a0022658

Robazza, C. (2006). Emotion in sport: An IZOF perspective. In S. Hanton \& S. D. Mellalieu (Eds.), Literature reviews in sport psychology (pp. 127e158). New York, NY: Nova Science. 
Robazza, C., \& Bortoli, L. (2005). Changing students' attitudes towards risky motor tasks: An application of the IZOF model. Journal of Sports Sciences, 23, 10751088. doi: 10.1080/02640410500128205

Robazza, C., Bortoli, L., Carraro, A., \& Bertollo, M. (2006). 'I wouldn't do it; it looks dangerous": Changing students' attitudes and emotions in physical education. Personality and Individual Differences, 41, 767-777. doi: 10.1016/j.paid.2006.03.020

Roberts, G. C., Treasure, D. C., \& Conroy, D. E. (2007). Understanding the dynamics of motivation in sport and physical activity: An achievement goal interpretation. In G. Tenenbaum \& R. Eklund (Eds.), Handbook of sport psychology (3rd ed., pp. 3-30). Hoboken, NJ: Wiley.

Ryan, R. M., \& Deci, E. L. (2000). Self-determination theory and the facilitation of intrinsic motivation, social development, and well being. American Psychologist, 55, 68-78. doi: 10.1037//0003-066X.55.1.68

Ryan, R. M., \& Connell, J. P. (1989). Perceived locus of causality and internalization: Examining reasons for acting in two domains. Journal of Personality and Social Psychology, 57, 749-761. doi: 10.1037/0022-3514.57.5.749

Standage, M., \& Ryan, R. M. (2012). Self-determination theory and exercise motivation: Facilitating self-regulatory processes to support and maintain health and well-being. In G. C. Roberts \& D. C. Treasure (Eds.), Advances in motivation in sport and exercise (3rd ed., pp. 233-270). Champaign, IL: Human Kinetics.

Treasure, D. C., \& Roberts, G. C. (2001). Students' perceptions of the motivational climate, achievement beliefs, and satisfaction in physical education. Research Quarterly for Exercise and Sport, 72, 165-175. 
Vallerand, R. J. (2001). A hierarchical model of intrinsic and extrinsic motivation in sport and exercise. In G. C. Roberts (Ed.), Advances in motivation in sport and exercise (pp. 263-319). Champaign, IL: Human Kinetics.

Vanden Auweele, Y, Bakker, F., Biddle, S., Durand, M., \& Seiler, R. (Eds.). (1999). Psychology for physical educators. Champaign, IL: Human Kinetics.

Wallhead, T. L., \& Buckworth, J. (2004). The role of physical education in the promotion of youth physical activity. Quest, 56, 285-301.

Walling, M. D., \& Duda, J. L. (1995). Goals and their associations with beliefs about success in and perceptions of the purposes of physical education. Journal of Teaching in Physical Education, 14, 140-156.

Wang, C. K. J., \& Biddle, S. J. H. (2007). Understanding young people's motivation toward exercise: An integration of sport ability beliefs, achievement goal theory, and self-determination theory. In M. S. Hagger \& N. L. D. Chatzisarantis (Eds.), Intrinsic motivation and self-determination in exercise and sport (pp. 193-208). Champaign, IL: Human Kinetics. 
Table 1

Descriptive Statistics, Partial Correlations (Controlling for Gender), and Alpha Coefficients

\begin{tabular}{|c|c|c|c|c|c|c|c|c|c|c|c|c|c|c|}
\hline \multirow[b]{2}{*}{ Measure } & \multicolumn{2}{|c|}{ Girls } & \multicolumn{2}{|c|}{ Boys } & \multirow[b]{2}{*}{1} & \multirow[b]{2}{*}{2} & \multirow[b]{2}{*}{3} & \multirow[b]{2}{*}{4} & \multirow[b]{2}{*}{5} & \multirow[b]{2}{*}{6} & \multirow[b]{2}{*}{7} & \multirow[b]{2}{*}{8} & \multirow[b]{2}{*}{9} & \multirow[b]{2}{*}{10} \\
\hline & $M$ & $S D$ & $M$ & $S D$ & & & & & & & & & & \\
\hline 1. Mastery climate & 4.11 & 0.42 & 3.92 & 0.45 & $(.70)$ & & & & & & & & & \\
\hline 2. Performance climate & 1.96 & 0.62 & 2.49 & 0.68 & $-.28^{*}$ & $(.78)$ & & & & & & & & \\
\hline 3. Task orientation & 4.06 & 0.56 & 4.13 & 0.60 & $.52 *$ & $-.24 *$ & $(.87)$ & & & & & & & \\
\hline 4. Ego orientation & 2.77 & 0.89 & 3.20 & 0.90 & .04 & .19 & .05 & $(.92)$ & & & & & & \\
\hline 5. Pleasant/functional PBS states & 2.39 & 0.70 & 2.73 & 0.64 & $.47 *$ & $-.28 *$ & $.57 *$ & .01 & $(.85)$ & & & & & \\
\hline 6. Unpleasant/dysfunctional PBS states & 0.44 & 0.39 & 0.52 & 0.59 & $-.22 *$ & $.39 *$ & $-.21^{*}$ & .10 & $-.39 *$ & $(.77)$ & & & & \\
\hline 7. Intrinsic motivation & 4.95 & 1.00 & 5.19 & 1.06 & $.52 *$ & $-.31^{*}$ & $.46^{*}$ & .04 & $.63^{*}$ & $-.44 *$ & $(.76)$ & & & \\
\hline 8. Identified regulation & 5.20 & 1.04 & 4.98 & 0.98 & $.26^{*}$ & $-.22 *$ & $.29 *$ & .08 & $.48^{*}$ & $-.28 *$ & $.64^{*}$ & $(.70)$ & & \\
\hline 9. External regulation & 2.17 & 1.15 & 2.62 & 1.42 & $-.25^{*}$ & $.22 *$ & $-.24 *$ & .11 & $-.22 *$ & $.38 *$ & $-.51 *$ & $-.38 *$ & $(.82)$ & \\
\hline 10. Amotivation & 1.63 & 0.78 & 2.32 & 1.25 & $-.22 *$ & $.37 *$ & $-.24^{*}$ & .00 & -.14 & $.41^{*}$ & $-.37 *$ & $-.24 *$ & $.63^{*}$ & (.79) \\
\hline
\end{tabular}

Note. Alpha coefficients are presented in brackets on the diagonal. $* p<.01$. 
Table 2

Psychobiosocial States as Predictors of Intrinsic Motivation, Identified Regulation, External Regulation, and Amotivation

\begin{tabular}{llllll}
\hline \multicolumn{1}{c}{ Psychobiosocial states } & $\beta$ & $\mathrm{R}^{2}$ & $\mathrm{R}^{2}$ change & $F$ change & $F$ sig. change \\
\hline Intrinsic motivation & & & & & \\
$\quad$ Active, dynamic (movement) & .30 & .31 & .30 & 69.91 & .00 \\
Happy, joyful, cheerful (emotion) & .32 & .46 & .14 & 41.12 & .00 \\
$\quad$ Socializing, collaborative (communication) & .14 & .47 & .02 & 5.13 & .03 \\
$\quad$ Fresh, reactive (bodily reaction) & .19 & .49 & .02 & 4.66 & .03 \\
Identified regulation & & & & & \\
Fresh, reactive (bodily reaction) & .25 & .22 & .21 & 43.51 & .00 \\
Socializing, collaborative (communication) & .26 & .29 & .07 & 14.73 & .00 \\
Active, dynamic (movement) & .23 & .31 & .02 & 5.51 & .02 \\
External regulation & & & & & \\
Awkward, clumsy (movement) & .26 & .16 & .13 & 23.62 & .00 \\
Lonely, isolated (communication) & .26 & .23 & .07 & 14.98 & .00 \\
Depressed, sad (emotion) & .16 & .26 & .03 & 5.77 & .02 \\
Doubtful, unsure, uncertain (performance) & .22 & .28 & .02 & 5.24 & .02 \\
Inactive, sluggish, passive (cognition) & .17 & .30 & .02 & 4.24 & .04 \\
Amotivation & & & & & \\
Lonely, isolated (communication) & .41 & .30 & .20 & 44.96 & .00 \\
Depressed, sad (emotion) & .22 & .38 & .09 & 22.24 & .00 \\
Awkward, clumsy (movement) & .23 & .41 & .02 & 5.98 & .02 \\
Doubtful, unsure, uncertain (performance) & .14 & .42 & .02 & 4.53 & .04 \\
\hline
\end{tabular}

Note. Gender is entered as covariate in the model. 
Figure captions

Figure 1. Serial multiple mediation. Task orientation and pleasant/functional psychobiosocial states mediate the relationship between mastery climate and intrinsic motivation/identified regulation. Standardized $(\beta)$ path coefficients are presented. $* p<.05, * * p<.01$.

Figure 2. Simple mediation. Unpleasant/dysfunctional psychobiosocial states mediate the relationship between performance climate and external regulation/amotivation. Standardized $(\beta)$ path coefficients are presented. $* * p<.01$. 